\title{
Contamination of irrigation systems of dental units with Cryptosporidium species in Alexandria, Egypt: a neglected disinfection pitfall
}

This article was published in the following Dove Press journal:

Risk Management and Healthcare Policy

16 August 2012

Number of times this article has been viewed

\author{
Azza Hassan' \\ Hanan Farouk' \\ Rashad Abdul-Ghani ${ }^{2,3}$ \\ Faika Hassanein' \\ 'Tropical Health Department, High \\ Institute of Public Health, Alexandria \\ University, Alexandria, Egypt; \\ ${ }^{2}$ Parasitology Department, Medical \\ Research Institute, Alexandria \\ University, Alexandria, Egypt; \\ ${ }^{3}$ Department of Medical Parasitology, \\ Faculty of Medicine and Health \\ Sciences, Sana'a University, Sana'a, \\ Yemen
}

Purpose: To investigate the contamination of the dental irrigation systems with Cryptosporidium species in Alexandria, Egypt.

Methods: Forty water samples from all 20 working dental irrigation machines in a dental center in Alexandria were included in the study. Water samples were taken from the handpieces of dental irrigation machines in all studied units. After filtration through a membrane filter, water sample residues were stained using modified Ziehl-Neelsen staining and examined microscopically for Cryptosporidium spp.

Results: Cryptosporidium spp. was found as a contaminant in $27.5 \%$ of water samples taken from dental irrigation machines.

Conclusion: This indicates a contamination by the public water supplies to which these dental irrigation machines are connected. This disinfection pitfall may pose an infection risk to those seeking dental care.

Keywords: Cryptosporidium, contamination, dental irrigation machines, Alexandria

\section{Introduction}

The specific structure of dental units favors the presence of biofilm and microbial contamination of dental unit water lines. ${ }^{1}$ Dental practices may be associated with the acquisition of a variety of infections; however, great interest has so far been focused on blood-borne agents, such as viruses. Cryptosporidium is an obligatory, intracellular, coccidian parasite that infects the intestinal epithelial cells, causing diarrhea. It is classified as an emerging pathogen by the Centers for Disease Control and Prevention, ${ }^{2}$ and can cause infection in people, cattle, and other animals. ${ }^{3}$ Cryptosporidium may be transmitted by direct person-to-person contact, contact with infected animals, or ingestion of contaminated water or food. ${ }^{4}$ The parasite can complete its life cycle within one host, and is known to be resistant to antiparasitic drugs. Upon infection with Cryptosporidium, immunocompetent individuals may experience a self-limiting, acute, watery diarrhea lasting for about a week; however, the immunocompromised typically develop chronic or persistent diarrhea, leading to wasting and even death. ${ }^{5}$ Further, chemotherapeutic agents have been shown to have low efficacy in those immunocompromised individuals who are most affected by the disease. ${ }^{6}$

The resistance of Cryptosporidium spp. to the typical concentrations of chlorine used to disinfect water has made this an important issue. ${ }^{7}$ The ability of Cryptosporidium oocysts to survive conventional water treatment, and to withstand chlorine disinfection, make control of water-borne infection particularly challenging in developed and developing countries alike. ${ }^{8}$ Many microbial studies have
Correspondence: Rashad Abdul-Ghan Parasitology Department, Medical Research Institute, Alexandria University, Egypt Tel +203591 8407

Email rashadqb@yahoo.com 
reported the presence of bacteria and biofilm formation in dental unit water lines. ${ }^{1}$ This prompted us to search for the possible contamination of dental irrigation systems with Cryptosporidium spp., one of the most commonly known water-borne parasites.

The availability of simple, inexpensive methods to detect Cryptosporidium spp. in the hospital environment may promote regular monitoring for the parasite in resource-limited countries. Modified Ziehl-Neelsen (MZN) is an inexpensive and readily available stain in Egypt. In the present study, we used MZN stain to detect Cryptosporidium spp. in water samples collected from the dental irrigation systems in a dental center. Despite its recognition as a risk factor to patients in dental clinics, contamination of irrigation water in such clinics has not been given any interest, and no previously published study has dealt with this topic. Therefore, the purpose of this preliminary study was to uncover such potential risk in the clinics of a dental health center in Alexandria, Egypt.

\section{Materials and methods}

The present study was conducted on dental irrigation machines in a dental center in Alexandria, Egypt, during the period from June to August, 2011. Forty $500 \mathrm{~mL}$ water samples were collected from the handpieces of all 20 dental irrigation system machines in the dental center, using sterile containers. Water samples were then filtered through sterile $0.45 \mu \mathrm{m}$ membrane filters (Sartorius Stedim Biotech, Goettingen, Germany) within 2 hours of collection. Smears were prepared from the residues collected on membrane filters, air-dried, and fixed. Duplicate smears were stained with $\mathrm{MZN},{ }^{9}$ according to standard procedures. The stained smears were then examined under a light microscope using $1000 \times$ magnification. At least, 200 oil immersion fields of the stained smears were examined for cryptosporidia.

\section{Result}

Cryptosporidium spp. was prevalent in 27.5\% (11/40) of water samples collected from the handpieces of dental machines.

\section{Discussion}

Conventional water treatment involving coagulation/ flocculation, sedimentation, filtration, and disinfection may not be sufficient to clear water contamination with Cryptosporidium spp. ${ }^{10}$ Therefore, Cryptosporidium oocysts may escape water-treatment disinfection procedures.
Recently, $15 \%$ of public water coolers have been found to be contaminated with Cryptosporidium spp., in Alexandria $^{11}$ indicating the contamination of public water supplies.

To our knowledge, the present study is the first report on detection of Cryptosporidium spp. in the irrigation systems of dental units. It was found that $27.5 \%$ of water samples from the handpieces of dental irrigation machines were contaminated with Cryptosporidium spp. This indicates the contamination of water supplies of dental units with this parasite. This is a particularly important finding because the infectious dose of Cryptosporidium is so low that only a few oocysts can initiate infection in healthy individuals. ${ }^{12,13}$

The connection of dental units to public water supplies necessitates the investigation of these units for possible contamination. The presence of Cryptosporidium spp. in the irrigation systems of dental units has clinical implications as it may be associated with diarrhea in those ingesting water contaminated with oocysts in such units. This is particularly important if the patients seeking dental care are immunocompromized or young children. To avoid possible infection with Cryptosporidium, water should not be delivered to patients via dental irrigation systems connected to the public water system. Instead, the use of independent water supplies and the provision of disinfected water in dental units are encouraged.

The result of the present study is limited by the fact that only morphological criteria were evaluated; nevertheless, this study is very important due to its preliminary nature. Further large-scale studies to investigate the viability of Cryptosporidium oocysts besides the molecular detection and genotyping of Cryptosporidium to the species and genotype levels in dental unit irrigation systems are recommended.

\section{Acknowledgments}

The authors gratefully thank those who provided assistance in the dental center.

\section{Disclosure}

The authors report no conflict of interest in this work.

\section{References}

1. Szymańska J, Sitkowska J, Dutkiewicz J. Microbial contamination of dental unit waterlines. Ann Agric Environ Med. 2008;15:173-179.

2. Guerrant RL. Cryptosporidiosis: an emerging, highly infectious threat. Emerg Infect Dis. 1997;3:51-57.

3. Davies AP, Chalmers RM. Cryptosporidiosis. BMJ. 2009;339: 963-967.

4. Griffiths JK. Human cryptosporidiosis: epidemiology, transmission, clinical disease, treatment, and diagnosis. Adv Parasitol. 1998;40: 37-85. 
5. Pantenburg B, Castellanos-Gonzalez A, Dann SM, et al. Human CD8(+) T cells clear Cryptosporidium parvum from infected intestinal epithelial cells. Am J Trop Med Hyg. 2010;82:600-607.

6. Mead JR. Cryptosporidiosis and the challenges of chemotherapy. Drug Resist Updat. 2002;5:47-57.

7. Rochelle PA, Marshall MM, Mead JR, et al. Comparison of in vitro cell culture and a mouse assay for measuring infectivity of Cryptosporidium parvum. Appl Environ Microbiol. 2002;68:3809-3817.

8. Chalmers RM, Campbell B, Crouch N, Davies AP. Clinical laboratory practices for detection and reporting of Cryptosporidium in community cases of diarrhoea in the United Kingdom, 2008. Euro Surveill. 2010; $15: 1-5$.

9. Casemore DP. ACP Broadsheet 128: June 1991. Laboratory methods for diagnosing cryptosporidiosis. J Clin Pathol. 1991;44:445-451.
10. Collinet-Adler S, Ward HD. Cryptosporidiosis: environmental, therapeutic, and preventive challenges. Eur J Clin Microbiol Infect Dis. 2010;29(8):927-935.

11. Hussein RA, Hassan AA, Bakr WM. Assessment of the quality of water from some public coolers in Alexandria, Egypt. J Egypt Public Health Assoc. 2009;84:197-217.

12. DuPont HL, Chappell CL, Sterling CR, Okhuysen PC, Rose JB, Jakubowski W. The infectivity of Cryptosporidium parvum in healthy volunteers. N Engl J Med. 1995;332:855-859.

13. Okhuysen PC, Chappell CL, Crabb, JH, Sterling CR, DuPont HL. Virulence of three distinct Cryptosporidium parvum isolates for healthy adults. J Infect Dis. 1999;180:1275-1281.
Risk Management and Healthcare Policy

\section{Publish your work in this journal}

Risk Management and Healthcare Policy is an international, peerreviewed, open access journal focusing on all aspects of public health, policy, and preventative measures to promote good health and improve morbidity and mortality in the population. The journal welcomes submitted papers covering original research, basic science, clinical \& epidemio-

\section{Dovepress}

logical studies, reviews and evaluations, guidelines, expert opinion and commentary, case reports and extended reports. The manuscript management system is completely online and includes a very quick and fair peerreview system, which is all easy to use. Visit http://www.dovepress.com/ testimonials.php to read real quotes from published authors.

Submit your manuscript here: http://www.dovepress.com/risk-management-and-healthcare-policy-journal 